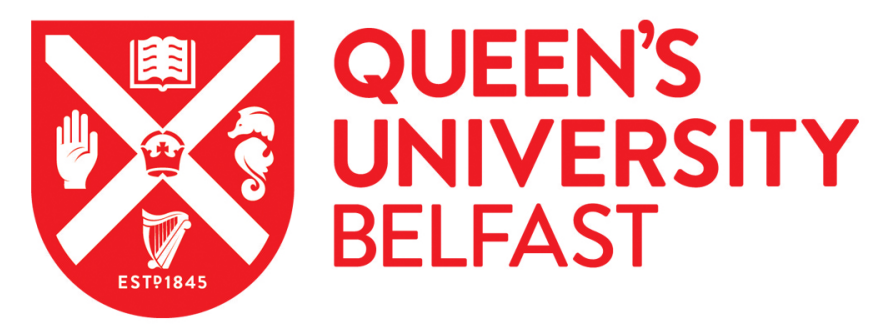

\title{
Improvisers, Incrementalists and Strategists: How and Why Organizations Adopt ADR Innovations
}

Roche, W., Teague, P., Gormley, T., \& Currie, D. (2018). Improvisers, Incrementalists and Strategists: How and Why Organizations Adopt ADR Innovations. British Journal of Industrial Relations, 57(1), 3.

https://doi.org/10.1111/bjir.12413

\section{Published in:}

British Journal of Industrial Relations

\section{Document Version:}

Peer reviewed version

Queen's University Belfast - Research Portal:

Link to publication record in Queen's University Belfast Research Portal

\section{Publisher rights}

(c) 2018 John Wiley \& Sons Ltd. This work is made available online in accordance with the publisher's policies. Please refer to any applicable terms of use of the publisher.

\section{General rights}

Copyright for the publications made accessible via the Queen's University Belfast Research Portal is retained by the author(s) and / or other copyright owners and it is a condition of accessing these publications that users recognise and abide by the legal requirements associated with these rights.

Take down policy

The Research Portal is Queen's institutional repository that provides access to Queen's research output. Every effort has been made to ensure that content in the Research Portal does not infringe any person's rights, or applicable UK laws. If you discover content in the Research Portal that you believe breaches copyright or violates any law, please contact openaccess@qub.ac.uk. 


\title{
Improvisers, Incrementalists and Strategists:
}

\section{How and Why Organizations Adopt ADR Innovations}

\begin{abstract}
This paper identifies three ways in which alternative dispute resolution (ADR) innovations are adopted by organizations in Ireland: improvisation, incrementalism and strategy, and examines how external and internal influences shape different patterns of ADR innovation. The paper contributes to the literature in three ways. First, it highlights the limitations of typologies of innovation based on simple dichotomies, such as reactive/proactive and of prevailing understandings of how ADR may interact with strategy. Second, the paper develops an integrated framework for the analysis of influences on patterns of innovation that distinguishes between the features of markets and commercial strategies, organizations, stakeholders and champions and institutions, laws and public policies. Third, the paper questions the central premise underlying the literature that a strategic approach to ADR equates with the adoption of conflict management systems.
\end{abstract}

Keywords: ADR, conflict management, mediation, conflict management systems. 


\section{Introduction}

Considerable uncertainty surrounds the manner in which organizations adopt alternative dispute resolution (ADR) innovations. An important strand of the literature has identified a 'historic transformation' in large US corporations, involving a shift from a 'reactive' to a 'strategic' approach to adopting ADR practices and the growing prevalence of 'systems' of innovations (Lipsky et al. 2016; 2014; 2012; 2003). It is recognized however that many organizations continue to adopt ADR innovations in a more reactive, piecemeal or ad hoc manner (Colvin 2003; Latreille 2001; Lipsky et al. 2003; Lynch et al. 2012; Saundry and Wibberley 2014; 2012; Teague et al. 2015). Other contributions reveal a pattern of adoption in which, once in place, innovations are seen to support wider organizational objectives than those animating their original introduction (Avgar 2016; Saundry and Latreille 2016). This paper seeks to break new ground by examining empirically the different ways in which organizations in Ireland have adopted ADR innovations and by identifying influences on different patterns of innovation. Drawing on the literature on ADR innovations, the paper focuses on three main research questions. First, what patterns of ADR innovation are evident in organizations in Ireland? Second, what influences shape patterns of innovation in different organizations? Third, drawing on a cross-case analysis, can distinctive sets or configurations of influences be identified that distinguish why different organizations follow different innovation paths? The paper contributes to the literature in three ways. First, it highlights the limitations of typologies of innovation based on simple dichotomies, such as reactive/proactive, and of prevailing understandings of how ADR may interact with strategy. Second, the paper develops an integrated framework for the analysis of influences on patterns of innovation that distinguishes between the features of markets and commercial strategies, organizations, stakeholders and champions and institutions, laws and public policies. Third, the 
paper questions the central premise underlying the literature that a strategic approach to ADR equates with the adoption of conflict management systems.

\section{ADR practices}

While definitions of ADR vary to some degree across countries and contributors (compare, for example, Acas 2005; Eurofound 2010 and Lipsky et al. 2003), the concept is commonly understood as encompassing practices and procedural arrangements that provide alternatives to litigation in the courts, or to resorting to administrative agencies (e.g. state conciliation agencies, employment or equality/equal opportunities tribunals) or labour courts where employment grievances or disputes arise. ADR practices are also sometimes understood as alternatives to conventional or long-established grievance or dispute resolution procedures in unionized or nonunion firms (Costantino and Sickles-Merchant 1996; Lipsky et al. 2003; Roche et al. 2014; Roche and Teague 2012; Ury et al. 1988).

Definitions of ADR practices for resolving grievances between individual employees and their employers commonly include formal open-door policies and speak-up practices, mediation, organizational ombudsmen and peer or management review panels. Also sometimes included is the training and proactive involvement of line managers and supervisors in troubleshooting and conflict resolution (Ewing 1990). ADR practices may also be adopted to prevent or respond to collective bargaining disputes with unions. Commonly included in this area are practices such as 'assisted bargaining', where external facilitators become involved at the outset or during the early phase of negotiations, fact-finding, interest-based bargaining and mediation-arbitration (usually 
shortened to med-arb). These practices again represent alternatives to conventional ways of conducting collective bargaining and resolving collective conflict.

ADR also commonly includes 'conflict management systems' (CMSs). CMSs are integrated sets of conflict management practices that couple together 'interest-based' and 'rights-based' conflict resolution options and that permit easy movement between the two processes. Interest-based options (for example, mediation) seek mutually acceptable solutions to grievances or disputes, whereas rights-based options involve adjudication as to whether a party involved in conflict suffered an infringement of their rights, as set down in employment contracts, collective agreements or deriving from prevailing social norms (Bendersky 2007; 2003; Conbere 2001; Roche and Teague 2012). CMSs are more commonly restricted to resolving grievances between individual employees and employers - even in unionized firms (Lipsky et al. 2003).

\section{How and why firms adopt ADR practices}

Commentators on ADR recognize that many and perhaps most organizations adopt ADR in an essentially improvised or ad hoc manner, reflecting a posture in which 'managing conflict is a reactive rather than a strategic choice' (Lipsky et al. 2003: 150), or in which organizations adopt a 'case-by-case approach' in deciding how to resolve grievances (Lynch 2001: 212). In this pattern, the take up of ADR is bottom-up, 'pragmatic', 'contingent', 'flexible' and 'reactive' (Colvin 2003; Lipsky et al. 2003: 141-4). Case studies of the adoption of mediation in the UK reveal that organizations commonly make improvised and piecemeal changes to conflict management procedures and practices - for example, by introducing mediation - when faced with specific problems or changes in the legal and regulatory environment, showing little appetite for more 
systematic changes on strategic or other grounds (Latreille 2011; Saundry and Wibberley 2014: 6, 2012: 35-6). Surveys of developments in ADR in several countries suggest that the dominant pattern of adoption appears to involve changes being made in a reactive, ad-hoc way, normally in response to a particular problem or development in the internal or external environment (Roche and Teague 2011; Roche et al. 2012; Wood et al. 2014).

Contributions to the ADR literature also point towards a different pattern of adoption, commonly without explicitly labeling this pattern. A synthesis of the findings of case studies of mediation in the UK identifies several organizations where mediation was used 'as a way of moving from a reactive to a more proactive mode of addressing conflict' (emphasis added). The operation of mediation in these organizations was viewed as a possible precursor to the evolution of integrated conflict management systems (Latreille 2011: 16; 63-4). In the case of the US, Lipsky et al. (2003: 144) identify instances where an initially pragmatic, piecemeal stance towards ADR was extended incrementally to encompass different types of disputes, and also other instances where unsatisfactory experience with new practices had stalled the wider use of ADR. These cases involve a pattern of adoption where organizations that had originally improvised piecemeal changes in conflict management practices subsequently aligned these with other conflict management practices or with HR strategy - in the process modifying, extending or sometimes abandoning original ADR innovations. The dynamic involved in this pattern was illustrated by two recent case studies of the adoption of ADR by healthcare providers in the UK and the US. In a UK health authority, 'Trustorg', the introduction of an internal mediation programme was the catalyst for the development of a CMS. The main sponsor of the mediation programme, a consultant occupational psychologist, occupied a pivotal position in the organization's response to 
occupational stress, extending the programme to proactive stress management. The CMS was seen to be an important asset in meeting strategic goals of the Trustorg, in particular combatting stress and fostering well-being (Latreille and Saundry 2016). In the US healthcare provider, Ohio Medical, the Federal Mediation and Conciliation Service (FMCS) sponsored the introduction of an organizational ombudsman who became pivotal to the development of a suite of interest-based ADR options. The resulting CMS again connected in important ways with strategic objectives of the organization, in particular, gaining certification as an outstanding or 'magnet hospital', recruiting and retaining nurses in a highly competitive local market and becoming an 'employer of choice' (Avgar 2016). The authors of these case studies highlight the strategic approach to the management of conflict that underlies the adoption of ADR practices (Latreille and Saundry 2016: 191). The pattern evident nevertheless was one of bottom-up innovation that was aligned in an iterative or incremental manner with wider strategic objectives of both organizations. In short, ADR innovations became strategic or evolved towards strategic significance in a manner that was evidently not originally considered.

What might be described as ‘incrementalism by design' formed the basis of a programme launched by the US FMCS in the early 2000s (Robinson et al. 2005). The 'Dynamic Adaptive Dispute Systems' (DyADS) programme, which was the spur to innovation in Ohio Medical discussed earlier (Avgar 2016), aimed to develop and diffuse conflict management systems in unionized organizations, with an explicit emphasis on 'incrementalism as a guiding premise' and 'bottomup' rather than 'top-down' design or redesign of conflict management practices: 'people are much less resistant to working on improving the way things are done, to introducing incremental change, or to trying new approaches within an existing system, than they are to signing on for a massive 
change effort' (Robinson et al. 2005: 358-9). Incremental initiatives 'focusing on smaller rather than larger reforms' were seen to have the capacity to evolve into 'major change' involving 'systems reorganization' (Robinson et al. 2005: 359). They might also stop short of this or even regress in the event that ADR innovations were judged ineffective.

We describe this pattern of ADR innovation as incrementalism because it involves organizations adopting ADR practices not in recognition $a b$ initio of their strategic significance, but rather initially in a reactive bottom-up manner and either extending these, where they are found to have beneficial outcomes or to be useful in the context of broader organizational goals, or discontinuing them where they are found ineffective or to clash with broader organizational goals.

A further pattern of adoption, identified mainly in the US, involves firms adopting ADR in a strategic manner. This pattern, which has informed influential analytical and prescriptive studies, is revealed by a survey of the adoption of ADR in US Fortune 1,000 firms. Here the adoption of ADR practices, particularly in the form of integrated CMSs, is understood as a 'function of proactive and strategic decisions and not simply [as] a reaction to external and internal pressures' (Lipsky et al. 2012: 5). In the same way, organizations adopting ADR are sometimes 'not merely pushed or pressurized into adopting innovative conflict management practices' but 'rather an organization's conflict management approach is also a function of proactive, strategic decisionmaking factors' (Lipsky et al. 2014: 5). Stakeholders, including unions, may be involved in the design of conflict management arrangements and this is commonly advocated in prescriptive versions of strategic ADR (Costantino and Sickles-Merchant 1996: ch. 4; Lipsky et al. 2014: 1601; Ury et al. 1988: 61-2). 
In this pattern the adoption of ADR results from top-down planning, deliberation and systemic change programmes, explicitly aligns postures towards conflict resolution with commercial strategy, and involves the creation of CMSs (Conbere 2001; Costantino and Sickles-Merchant 1996; Lipsky et al. 2016; 2014; 2012; 2003; Lynch 2001; Ury et al. 1988).

Table 1 presents an outline of the key features of three patterns of innovation that have been distinguished or that are distinguishable in the literature. We next examine influences on the adoption of ADR practices by organizations identified in the literature.

[Table 1 here]

\section{Markets and Commercial Strategies}

Highly competitive and especially global product markets may lead organizations to seek cost reductions and efficiencies, including reductions in costs arising from conflict. As a result, such conditions may predispose organizations towards strategic patterns of innovation (Lipsky et al. 2016; 2012; 2003). Discontinuous changes in markets arising, for example, from deregulation, may also predispose organizations to seek more strategic approaches to managing conflict (Lipsky et al. 2003). Incrementalism appears to occur in less competitive or discontinuous organizational environments (Avgar 2016), although pressure on NHS budgets and the search for efficiencies and higher performance were identified as significant influences in the case of Trustorg (Latreille and Saundry 2016). The FMCS's DyADS model proposed that incremental innovation was more appropriate to gradual than to discontinuous environmental change (Robinson et al. 2005: 357). 
How organizations seek to position themselves in labour markets may also affect patterns of innovation. Where organizations compete for talent, seek to address staff retention problems and position themselves as 'employers of choice', they may also be predisposed towards bottom up incremental or towards strategic approaches to adopting ADR (Lynch 2001; Avgar 2016). However, essentially the same posture has been associated with the more improvised or ad hoc adoption of mediation or other singular practices (Colvin 2004b; 2003; Latreille 2011: 17).

The commercial strategies of organizations are also seen to have significant effects on some patterns of innovation. The general premise is that strategic approaches to ADR, involving the creation of CMSs, are more likely where organizations adopt 'high-end' competitive postures where innovation and/or quality are priorities, and where organizational effectiveness is premised on high levels of employee engagement that would be seriously impaired by workplace conflict (Colvin 2004a; Cutcher-Gershenfeld et al. 2007; Latreille and Saundry 2016: 195; Lipsky et al. 2003: 7; Roche and Teague 2011; Teague et al. 2012). High-end commercial strategies, or their equivalent in not-for-profit organizations, have also been associated with the incremental development of CMSs (Avgar 2016; Latreille and Saundry 2016). Organizations strategically committed to gaining and maintaining a reputation for corporate social responsibility are also shown by Lipsky et al. (2012) to be more likely to adopt CMSs - the two being connected, it is argued, by an organization's responsiveness to the interests of external and internal stakeholders.

\section{Organizations, Stakeholders and Champions}


A build-up of disciplinary incidents and employment grievances, or impatience with endemic adversarial or confrontational employment relations cultures have been identified as influences on the improvised adoption of mediation, as well as on incremental innovation (Avgar 2016; Latreille 2013: 17; Latreille and Saundry 2016; Robinson et al. 2005). ${ }^{1}$ Organizational crises including major and costly lawsuits and disputes, have consistently been identified as precipitating strategic innovation, involving in most cases the adoption of CMSs (Lynch 2001: 211; Latreille and Saundry 2016: 200; Avgar 2016: 220; Lipsky et al. 2003: 137-8). Other precipitating events, such as fiscal crises or legislative changes that pose exceptionally difficult problems for collective bargaining, have been associated with the diffusion of collective ADR practices such as facilitated interestbased bargaining in the US public education sector (Klingel 2003: 20).

Organizational cultures of 'conflict competence', as well as initiatives directed at the evidently strategic objective of cultural transformation, have been identified as influences on both the strategic and the incremental adoption of ADR in a variety of settings and across a number of countries, although the direction of causation may also run from the adoption of ADR to the creation of such cultures (Deukmedjian, 2003; Latreille and Saundry, 2016; Lynch, 2001; Lipsky et al., 2003).

Studies of the incremental development of CMSs suggest that ADR innovations such as mediation programmes or the creation of ombuds offices may positively spillover to wider management practice or employment relations. These contribute to organizational learning that then becomes instrumental in embedding and further extending ADR practices into such areas as line managers'

\footnotetext{
${ }^{1}$ Such conditions have sometimes been equated with 'crisis' (see Latreille 2011: 15).
} 
conflict competencies and management-union relations (Avgar 2016; Latreille and Saundry 2016; Robinson et al. 2005).

The manner in which work is organized has been identified as a contributor to the adoption of ADR. The main contention here is that new forms of work organization, such as team working, predispose organizations towards a strategic approach to conflict management because 'collaborative' forms of work organization put a premium on conflict prevention and resolution (Lipsky et al. 2016; 2003; Kaminsky 1999). At the same time, the imposition of tighter managerial controls over work discipline and performance management has also been associated with an incremental approach to ADR. Because tighter control triggers more employment grievances, using ADR to address these grievances assumed a new urgency (Latreille and Saundry 2016: 206). But it has been changes in work organization and management practices which, while resulting in more conflict, have led organizations to react by introducing mediation alone (Latreille 2011: 10).

An abiding theme in the US literature concerns the use of ADR practices sometimes as a means of pursuing ‘union substitution' (Lipsky and Seeber 2000; Lipsky et al. 2003). However, it has emerged that ADR may also complement conflict management arrangements in unionized organizations or be introduced, with union support, in an effort to forge a new relationship with unions (Avgar 2016; Lipsky et al. 2016; 2012; Latreille and Saundry 2016; McAndrew 2014; 2012).

The literature sometimes represents the uptake of ADR as a feature of the emergence of a more professional or proactive HRM (Lipsky et al. 2003: 61-2) and HR managers figure as important if 
not altogether enthusiastic players in a number of accounts of the incremental and strategic adoption of ADR (Avgar 2016; Latreille and Saundry 2016; Lipsky et al. 2003). The literature also consistently points to the influence of 'champions' on the adoption of ADR, whether these operate within top-level management, senior management teams, the HR function or other parts of organizations (Lipsky et al. 2016: 298; 2003: 135-6; Latreille and Saundry 2016: 203-4; Lynch 2001: 210). 'Champions' also figure, however, in accounts of the adoption of isolated mediation programmes ADR that stop well short of wholesale strategic change (Latreille 2011: 19-20.)

\section{Institutions, Laws and Public Policies}

Conformity with external changes in regulatory conditions, or seeking to avoid breaches of employment law and litigation have been identified as significant for the adoption of mediation in UK organizations and on the strategic uptake of ADR practices by US firms (Lipsky et al. 2012; Saundry and Wibberley, 2014: 30 but cf. Avgar 2016).

Public policies and initiatives by state conflict resolution bodies have also been shown to play a significant role in the diffusion of ADR: whether by encouraging the use of mediation or facilitated collective bargaining, or by sponsoring incremental or strategic approaches involving the development of CMSs (Avgar 2016; Brown 2014; Cohen 2011; Latreille and Saundry 2016; Robinson et al. 2005). Finally, institutional and legal arrangements beyond the boundaries of organizations may also be important in influencing the manner in which ADR practices are adopted. The international literature suggests that the strategic adoption of CMSs by organizations may be shaped to a significant degree by institutional features of US employment relations. These include the high costs of employment litigation, long delays in concluding hearings, very large awards and the 1991 US Supreme Court ruling in the Gilmer case which makes it legally 
permissible for organizations to require employees to resolve legally-based employment grievances through their internal conflict resolution procedures (Colvin 2012). This external institutional context builds powerful incentives for treating conflict in a strategic manner and for the effective resolution of employment conflict inside organizations. The ease of access in other national settings to employment tribunals, state dispute resolution services and labour courts may create incentives to externalize conflict resolution to a significantly greater extent than in the US and act as a disincentive to internalizing conflict resolution.

The literature prompts a series of research questions that will focus our analysis of the adoption of ADR innovations by organizations in Ireland.

1. In what ways have organizations adopted ADR innovations and are clear patterns of innovation evident in the experiences of organizations with the uptake of ADR?

2. What influences are evident on different patterns of innovation in Irish organizations?

3. Can different patterns of innovation be linked with different sets or configurations of influences when a cross-case analysis in conducted?

\section{Research methods}

To examine the ways in which organizations in the private and public sectors in Ireland introduced ADR innovations, we adopted a multi-method qualitative research design that collected data through interviews and focus groups and a series of case studies. Details of data collection methods are contained in Table 2 . 
[Table 2 here]

The interviews were conducted with multiple stakeholders involved in the adoption and operation of ADR: managers, employer representatives, union officials and conflict resolution professionals. Interviews were conducted with regional officers of the main Irish employers' federation, the Irish Business and Employers' Confederation (IBEC), responsible for providing HR and industrial relations support and advice to affiliated organizations. A review of trade union websites and internal telephone directories generated a listing of 157 full-time union officials involved in frontline representation and negotiation. Of these seventy-two, or 46 per cent, participated in telephone interviews in May 2013. Participants in the focus groups were chosen from a list derived from coverage in the industrial relations media of organizations and people involved in the introduction and implementation of ADR innovations, especially as reported in the weekly periodical, Industrial Relations News. All facilitators working with the state conflict resolution body, the Labour Relations Commission (since renamed the Workplace Relations Commission), as well as all identified private facilitators working in Ireland, were also interviewed. In all 153 practitioners with direct experience of conflict management participated in the survey and focus group strand of the research. All interviewees were asked a series of questions relating to the degree to which, in their experience, organizations were adopting ADR innovations; the kinds of ADR innovations being adopted and the reasons why innovations were being adopted.

The provision of research data by multiple stakeholders operating across a range of industries represents a major strength of the research design in a field where data is commonly obtained from 
management respondents or confined to the parties involved in small numbers of case studies. Data generated by a range of stakeholders also allows for the correction of 'bias' with respect to the nature and genesis of ADR that would arise from an exclusive focus on any one stakeholder group: managers, union representatives or ADR professionals.

Interviews with the stakeholders were also used as a means of identifying potential case study organizations for intensive study. Generating a population of case study organizations was recognized to be a key feature of the research design and so was conducted in a highly systematic manner to ensure that the cases selected were representative of the full spectrum of ADR innovations evident in Ireland. Our focus in the case study research remained on understanding the kinds of ADR innovations being adopted by organizations and why these were being adopted. Case studies were selected for study from a population list of all known instances where organizations had introduced ADR practices. The population list was compiled from a series of sources. These included reports in Industrial Relations News, media and press reports, cases presented at $\mathrm{HR}$ and industrial relations conferences. Discussions with conflict resolution professionals were also undertaken to identify cases. Further cases identified in telephone interviews with IBEC officers and union officials and that emerged in focus group discussions were added to the master list of ADR innovations. The list was stratified by the types of innovation(s) involved, providing sub-lists of cases of mediation, assisted bargaining, proactive line management involvement and involving multiple ADR innovations. Case studies were then chosen for intensive study from this stratified list based on a combination of ensuring as wide as possible a spectrum of sectors and organizations and achieving access to the required data. 
In our view no hitherto existing study of ADR has adopted such a careful approach to generating and selecting case studies; the prevailing approach in the area has involved the reporting of exemplary cases. We are satisfied that the careful and systematic procedure adopted avoided case selection bias and we are confident that the cases chosen for study reflect the spectrum of ADR innovations to be found in Ireland. Interviews with employer representatives were transcribed. All other interviews were recorded and transcribed. Case study interviews were supplemented by internal and by publicly available information on the organizations. Interview data were analyzed on the basis of the themes and issues presented to interviewees in semi-structured interview questionnaires (individual interviews and case study interviews) and in power point overviews of interview themes (focus group interviews). Case study data were analyzed using the classical 'triangulation' methodology combining case study interviews with external and internal data on the organizations involved.

[Table 3 here]

Details of 8 case studies presented in the paper are listed in Table 3. The names of organizations are used with the permission of the parties involved. With the exception of the Central Bank, all targeted case study organizations agreed to participate in the study. Detailed reportage of multiple ADR developments at the Bank was available through publicly available reports and documentation, through the industrial relations media and from conference presentations by key initiators of ADR innovations within the Bank. It was decided therefore to examine the case in the absence of direct access. 
The fieldwork was undertaken during the period from March 2013 to March 2015. The authors are satisfied that the scale, range and depth of the fieldwork undertaken provide for a highly reliable portrayal and understanding of the manner in which ADR innovations have been adopted by organizations in Ireland. We are aware of few studies in the international literature on ADR that have been able to draw on such a range of data sources, or on such detailed accounts of ADR innovations provided by the people directly involved.

\section{Research Results}

In reporting the results focused around research questions 1 and 2, we begin by outlining data from direct and focus group interviews on the nature of and reasons for ADR innovations by organizations and we then examine in more detail the dynamics behind the patterns of innovation by drawing on the findings that emerged from case study organizations. Then we address research question 3 by presenting a systematic cross-case comparison of external and internal influences on patterns of innovation in case study organizations with a view to highlighting the different configurations of influences that shape each pattern of innovation.

HR managers and trade union officials, as well as facilitators, observed that organizations often responded to specific external and internal challenges to existing practices, or to existing shortcomings in procedures, by making changes to one area or facet of conflict management, without seeing the need to introduce complementary changes in other areas. In this way, innovations often involved responses to specific challenges or problems and were confined to one area or practice. Thus, for example, the rising incidence of individual grievances in areas such as 
bullying, harassment and discrimination were viewed as necessitating some type of adjustment to conventional procedures through the adoption of a new practice such as mediation. But HR managers and trade union officials also reported that mediation was generally resorted to on an ad hoc basis, without any, or with minimal, revision to formal agreed grievance procedures. One trade union official said 'I wouldn't believe that there's a [formal] grievance procedure in a unionized environment that specifies mediation as an option.'

Innovations in the management of collective conflict, such as the involvement of external facilitators in collective bargaining, also occurred without complementary changes in other areas of conflict management. Employers and unions sometimes opted for external facilitation when confronted with what one union official described as 'non-standard IR issues', including complex restructuring and change programmes that required 'a lot of teasing out' and that 'take companies outside their comfort zone.' A facilitator explained: 'If they have ... a big restructuring programme it might take months. ... They'll say will you facilitate talks on this?' Again these innovations in collective ADR were often, reactive, informal and piecemeal in nature: innovation did not follow the pattern of beginning with strategic reviews followed by comprehensive changes to better align conflict management practices with wider strategic and commercial goals. One trade union official summed up the prevailing view when he said 'my experience is that most (innovation) has been driven by dire need [rather] than any voluntary embracing of a new world.'

HR managers from both unionized and non-unionized firms provided insights as to why improvisation of this kind occurred. In their view, firms generally adopted a pragmatic approach to ADR innovations because workplace conflict was considered to be under control, obviating the 
need for any radical move away from tried-and-tested policies. Many HR managers even expressed unease about the vocabulary of innovation: one said, 'there is an issue about innovation, is it a long process? Have we time to do it? Does it actually work? Are we prepared to try it?' Another commented '... innovation is great as long as it doesn't turn into time wasting or ... a tool preventing you from implementing something.' HR managers' comments were echoed by facilitators and mediators. In their view employers and unions sought pragmatic solutions to problems. On the whole they saw little or no concern to integrate new ADR practices into existing procedures. A facilitator working in a state agency assisted unions and managers in a pharmaceutical company and commented that the 'company had a particular view' that the facilitation initiative was a stand-alone process. The facilitators interviewed could think of no case where 'assisted bargaining' involved, or arose from, strategic or systematic initiatives to reconstruct employment relations or conflict management procedures.

The case studies of Bus Eireann, the HSE, and the HSE Dublin, North East region outlined in Table 3 provide evidence of the occurrence of an improvisation pattern in the adoption of ADR and highlight the kinds of influences associated with this pattern. In the state-owned bus company, Bus Eireann, mediation was introduced to tackle instances of bullying and harassment in the wake of changes in the regulatory environment brought about by the Employment Equality Act (1998), the Equality Act (2004) and the Dignity at Work Charter issued by the Health and Safety Authority (2007). No related changes were made to conflict management arrangements or to the formal grievance procedure, although mediation was sometimes used at the informal stage for grievances other than bullying and harassment. Nor were any other changes made to human resource management or industrial relations practices or arrangements. In the case of the Health Service Executive (HSE), mandatory arbitration was introduced for individual grievances and collective 
disputes under the terms of a national public service agreement with trade unions in 2010. Though radical in its effects in speeding up grievance and dispute resolution and hailed by management as a 'game changer', the introduction of arbitration did not arise from or trigger internal change in organizational, HR or industrial relations strategy within the HSE. Nor had it prompted any revision of established conflict management arrangements within the HSE.

Facing a stalemate over a complex and highly politicized negotiating agenda concerning changes to the provision of acute hospital services for a population of around one million people, management and unions in the HSE Dublin North East Region engaged facilitators from the LRC to assist with unblocking the collective bargaining process. Through assisted bargaining, agreement was reached on the reconfiguration of hospital services. Though viewed as highly effective by the parties, resort to assisted bargaining was a one-off measure that led to no changes in the agreed formal conflict management procedure and reflected no wider changes in HR or industrial relations strategies.

Overall the interview, focus group and case study findings confirm that improvisation is a commonly occurring pattern of innovation in the use of ADR and that this pattern often occurs where revisions to existing practices are prompted by singular external influences, such as regulatory changes, whether arising from changes in laws or codes of practice, as in the case of Bus Eireann, or in national collective agreements, as in the case of the HSE, or deadlock surrounding existing practices, as in the case of HSE Dublin North East. 
The interview and focus group data also revealed a pattern of innovation consistent with incrementalism. HR managers revealed that they frequently treated individual innovations as provisional in nature and were prepared to adapt and modify ADR practices when they were confident that these were effective in addressing the problem they were created to resolve. As one HR manager explained 'we've used externals [external mediators]. One of them almost ran away screaming saying he never wanted to see us again ... . He was very successful, but he had enough of both sides!' Instead, internal staff members were trained up to deliver mediation, which turned out to be a more effective and cheaper way to operate the service.

Three of the cases in Table 3 displayed features associated with incrementalism. The Irish multinational food wholesaler and retailer, Musgrave, traditionally pursued organizational change by negotiating with trade unions. However, senior managers became increasingly concerned that collective bargaining as traditionally practiced in the organization was failing to deliver change at the rate required to keep up with the increasingly competitive retail market. Low-cost competitors such as Aldi and Lidl had increased their market share and patterns of consumer behaviour adapted to the recession - what Musgrave called 'modest shopping' - had put the company on the defensive.

To address this competitiveness challenge, senior managers introduced a major employee engagement strategy, a key part of which was to change schedules so that each line manager worked consistently with the same team: 
I was fairly insistent that the line manager would run along or work along with the team. I tried to move away from this idea of having a structure where a line manager came in and whoever was in on the day they just managed that team. (Senior HR Manager)

Line managers became involved for the first time in 'start-up meetings' when shifts changed, monthly 'huddles' where they updated their teams on their priorities and objectives, regular 'oneto-one' meetings with their reports and other such problem-solving and trouble-shooting practices. According to a senior HR manager, each line manager was expected now also to be a team leader, who would 'know the team members individually; sitting with them doing their appraisals etc.'

At the same time, line managers also became increasingly involved in identifying potential problems and resolving such grievances as did arise. A senior operations manager says of the line managers that they have 'worked with their teams building up the level of trust; we talk about conflict resolution, obviously we have conflict within the depot, obviously there are issues that arise but in the main we're almost at a point of conflict avoidance.' This tilt towards informal problem solving spilled over onto the organization's formal conflict management procedures. In particular, senior managers realized that line managers had to receive more comprehensive training to upgrade their problem-solving capability, and that the HR function needed to monitor actively whether informal conflict management was being conducted more or less the same way across the organization. Thus, conflict management changed significantly in the organization: informal conflict was widespread but for the first time line managers were involved in problem-solving. A spillover dynamic was evident whereby a change unrelated directly to conflict management had the effect of triggering quite significant yet incremental change to the way conflict was addressed in the organization. 
The genesis of mediation in Aramark Ireland was similar to that in Bus Eireann. In Aramark, however, a new practice that started out through a process of improvisation was subsequently aligned with corporate HR strategy and identified for wider diffusion across the multinational. Mediation had originally been adopted in Aramark's Irish subsidiary for grievances concerning bullying and harassment in the wake of changes in the regulatory environment similar to those that had prompted its introduction in Bus Eireann. The scope of mediation subsequently expanded to include other areas of interpersonal conflict. Proclaiming its commitment in its international operations to adopt best-practice HR and CSR, Aramark adopted the mediation process pioneered in its Irish subsidiary as part of a corporate-wide approach to conflict management. As a senior manager said, 'One Aramark means we've one way of doing things so regardless of where employees sit we manage them in the same way. Mediation is provided to our employees regardless of where they work, recognition is applied to all our employees regardless of where they work. So that's a journey that we're on.' The Aramark case shows that influences beyond experience with the specific ADR practice adopted, in this case a firm's evolving wider HR priorities, can also become a catalyst for incrementalism. In the case of Aramark a concern to align conflict management practices with HR or CSR strategy had not been the original spur to innovation. As outlined, innovation had originally been reactive to regulatory changes. Once adopted and judged to be effective, mediation was subsequently seen to align well with evolving HR strategy and to connect with wider strategic aims of the parent multinational firm.

The ICT firm, Eircom (since rebranded as 'eir'), illustrates a further instance of incrementalism. In this case, mediation was again adopted in response to external regulatory change of the kind 
already outlined in the cases of Bus Eireann and Aramark. However, it was subsequently adapted to become one of a suite of HR policies devised to handle the firm's ongoing transition from a public service bureaucracy with strong trade unions to a commercial organization with both unionized and non-union staff. Mediation came to be regarded by some in senior management as a means of symbolizing and prioritizing the individualization of employment relations and as a way of promoting the adoption of common HR practices across the firm's divisions and workforce. One manager suggested that strengthening and enlarging the role of mediation in the organization '[is] really the formalization of practices that have grown but [now] at the core of our approach is that we see employees as individuals. If you keep going back to that fundamental principle and you treat them that way you can find solutions.' While mediation was not formally enshrined in joint employer-union grievance procedures, the policy was transformed from being a stand-alone policy to one that dovetailed with an evolving HR strategic objective focused on recasting employment relations at Eircom.

Data obtained from telephone interviews, focus groups and case studies suggest some occurrences of more strategic patterns of ADR innovation. Thus, some non-unionized organizations, such as Intel, instituted corporate conflict management practices, involving combinations of intensive communication and three-step grievance procedures, in part to avoid having to engage with external statutory dispute resolution agencies. In these cases, a strategic approach to ADR innovation was seen to have been driven above all by a desire to keep work problems within the organization. One HR manager quipped 'going outside is just a nightmare... so much time, so much money... it was the worst event of my life.' Another remarked that if a workplace problem 'goes external, it may mean that senior managers have to go and sit in Court...or a Tribunal and that is like, I mean, [they] might as well just go and sit on the stove for a week.' 
Two of the case studies presented in Table 3 involve patterns of ADR innovation that can meaningfully be portrayed as strategic, although neither involve fully-fledged CMSs. Innovations in the Central Bank seem on the face of it closest to the kinds of conflict management systems associated with strategic conflict management and CMSs in the literature. In 2008-2009 the Central Bank was plunged into organizational crisis as a consequence of the Bank's weak oversight and regulation of the Irish financial system, which resulted in the radical restructuring of the national financial regulatory regime and of the Bank. Though human resource deficiencies were not identified in any explicit way as the source of the Bank's shortcomings, a new human resource strategy was developed for the newly configured organization. Following an admonition by the Labour Court that the Bank's 'reputational crisis' warranted a 'radical [industrial relations] response', a new industrial relations model based on problem solving and information sharing was developed for the organization. As one manager put it, there needed to be a move towards 'less open warfare and more collaboration and joint ownership'. This included a new collective dispute resolution procedure that made provision for disputes to be adjudicated by an internal tribunal. The remit of the tribunal was expanded to include internal conciliation after it was used to solve a contentious dispute in 2013. An external dispute resolution professional was engaged to advise on the establishment of the internal tribunal. The Bank and its unions also agreed a new internal mediation programme for resolving individual grievances, as well as a new external appeals process for grievances over performance ratings. While these changes were prompted by a strategic change in the Bank's underlying employment relations model, the pattern of innovation was also different in important respects from that set down in the strategic paradigm that dominates the literature. The innovations at the Central Bank had their genesis in a major strategic change 
programme but were also introduced serially and operated on parallel rather than on convergent tracks. To date, no attempt has been made to align the changes made into an integrated conflict management system.

Developments at the computer chip manufacturer, Intel, also appear strategic in their handling of conflict management. Globally and in its Irish operations Intel operates a high-commitment HR strategy that supports an innovation-based commercial strategy and that includes an explicit policy of union avoidance and a set of ADR practices, in particular an open-door policy comprising internal 'interest-based' and rights-based practices for resolving grievances. In the early 1990s, senior managers at Intel's Irish subsidiary became concerned that the open-door policy was not functioning well. A review by HR at the subsidiary led to the creation of the new role of 'employee relations specialists' (ERSs) within the HR department. ERSs provided support and advice for employees involved in the open-door process, while other HR specialists, designated as 'business generalists,' advised business managers on best practice and legal compliance. Over time, concerns developed that although successful in resolving a very high proportion of grievances, the open door policy was also leading to line managers abdicating their responsibility to resolve grievances informally and promptly.

As a result, conflict management was once again changed to what has become known as the 'dual focus model'. This change sought to reduce the formality involved in handling grievances and to strengthen line management engagement in conflict resolution. The dual focus model replaced employee ERSs and business generalists with a single integrated HR team with the 'dual' role of providing support to both employees and managers involved in disputes. A key principle of the 
modified procedure was the reinstatement of the primacy in conflict resolution of the employeeline manager relationship. As a senior HR Executive commented: 'In my opinion they are absolutely crucial and their skill, expertise, willingness to do so and ability to do it is just absolutely to the front.' More recently, the HR team has developed a system for collecting and analyzing data on 'conflict indicators' to identify areas for proactive intervention to manage conflict more effectively. Intel is a case where conflict management is vertically integrated with commercial strategy, laterally integrated into the blueprint provided by the firm's wider HR model and subject to blueprint-guided review and revision when problems are identified and products or production processes change. The HR team at Intel is of the view that on-going changes and modifications are required to ensure that the organization's conflict management system remains aligned with broader corporate strategy. As one HR manager commented: 'as the factory changes, as the technology changes, as pressure comes on we adapt, we figure out what it is that we need to tweak and we just do it. There's a lot of it happens almost by osmosis you know, changes are made ... tweaks are made. Go back and relook at that, maybe it isn't giving us what we need and we do something else, bring in a different programme. This just happens.'

Overall, the Central Bank and Intel cases reveal the nature of strategic conflict management in two major organizations and suggest that somewhat different sets of external and internal influences can lead to conflict resolution being treated in a strategic manner. In the case of the Central Bank, organizational crisis and sharp discontinuities in the external environment led to a more strategic approach to conflict resolution, with an external agency, the Labour Court, also acting as a catalyst for innovation. In the case of Intel, strategic conflict management arose directly from the firm's HR and union substitution strategy and ongoing changes to the set of ADR practices reflected both 
evolving experience with ADR and a strategic concern to align ADR with commercial challenges facing the firm. The focus group finding that strategic conflict management might also reflect an aversion to externalizing conflict resolution and appearing before courts and tribunals also seems consistent with such an approach.

\section{A Cross-Case Analysis of Influences on Patterns of ADR Innovation}

To answer research question 3, we further investigate why patterns of ADR innovation differed across organizations. The focus here is on how internal and external influences on innovations combined or interacted when the research case studies are systematically compared. The comparison further reveals the distinctive configurations of external and internal influences shaping patterns of innovation. Table 4 uses the analytical framework derived from the literature to highlight the external environmental and internal organizational influences that shaped the different patterns of innovation identified in the case studies.

[Table 4 here]

Bus Eireann was sheltered from competition across part of its operations through a public subvention covering routes that were not commercially viable and through direct funding of its school bus service. While the company faced growing competition on its commercial inter-city bus services and later a significant squeeze on its public subvention payments, market and commercial conditions reflected long-run trends and could not be viewed as discontinuous during the period when mediation was adopted in 2005. The HSE, including HSE Dublin North East, are publicly-funded health services and health spending was relatively insulated from cuts in public 
spending following the onset of the Irish economic and fiscal crisis in 2008 (Kinsella 2017). Only HSE Dublin North East, however, instituted a major restructuring programme. This had been planned prior to the crisis, affected the region's acute hospitals and resulted in the request for assisted bargaining.

Improvisers were largely passive with respect to labour market positioning and pursued commercial strategies and provided services that were heavily price or cost constrained, limiting the extent to which proactive or systemic modes of conflict management were considered a feasible priority. Organizations, stakeholders and champions were also distinctive in the case of improvisers. Bus Eireann and the HSE remained wedded to a 'pluralist' model of employment relations in which conflict was viewed as an endemic feature of organizations to be managed in a pragmatic way. This posture encouraged improvisation and discouraged more incremental or systemic innovation.

The improvisers possessed largely administrative or transactional HR functions, where there was little impetus for innovation short of improvised adaptation in the light of external developments. None of the improvisers possessed managers (or union representatives) with a strong interest in ADR, or concerned to foster best practice in conflict management. Pressure for improvised ADR innovations arose directly from regulatory changes in the case of Bus Eireann and the HSE and from the collective bargaining deadlock surrounding hospital restructuring in the case of HSE Dublin North East. The LRC's reluctance to engage in conventional conciliation under the prevailing dispute procedure was a major spur to using facilitation. As a senior HSE HR Executive put it regarding the stance of a key LRC officer: 'you're not going to come in here and get us 
involved in a dispute around numbers that we know nothing about.' At the same time the LRC's involvement provided little incentive for more radical or long-lasting changes in conflict management practices.

Incrementalists operated in more competitive and more discontinuous markets and commercial conditions than improvisers and were characterized by commercial postures where a corporate reputation for quality was significant - albeit to varying degrees and in different ways. Thus, Aramark positioned itself globally as a firm with highly developed CSR policies. Musgrave sought to respond to declining profits and growing competition, especially from 'discount supermarkets', which threatened to transform the market. It also changed its business model: it had previously operated a franchise model, with a network of 600 stores, some of them directly owned but the vast majority of them independent; now it bought the Superquinn chain of supermarkets, and moved closer to being a direct retail chain. Yet in terms of corporate structure it remained a familyowned firm, rooted in a well-defined corporate ethos, which reflected the paternalist values of its Methodist founders, articulated as 'long-term commitment', 'shared success', 'respect' and 'integrity'. Musgrave squarely positioned itself as a 'good employer'.

The firm responded to changing market conditions and pressure for lower product prices on shelves with a new commercial strategy, Winning in the New World, which envisaged the creation of a high-performing organization capable of driving long-term profitability and which identified growing the business, employee engagement and talent management as strategic priorities. While senior managers expressed impatience with change management via collective bargaining and very limited line engagement in dealing with HR issues, a new approach to conflict management or 
ADR were not explicit objectives in its newly adopted organizational change strategy. As a senior HR manager expected, the strategy did in fact lead to reduced levels of conflict but 'it wouldn't be explicitly in it but was implicit that the benefit for the line manager [working] along with the team was that there'd be less conflict.' Therefore the firm's new engagement strategy, through a process of spillover, brought line and supervisory managers into direct contact with problem-solving and conflict resolution that cumulatively obliged Musgrave not only to provide more systematic training to line managers in these new activities, but also to rework the relationship between formal and informal conflict management in the organization.

Eircom operated in a fast-moving quality- and price-competitive ICT service market and was in transition from a former public service bureaucracy to an aggressively commercial organization. In particular through the recruitment of software engineering and sales staff for the firm's mobile networks and the acquisition of the mobile firm, Meteor, there was a shift towards recruiting staff with a private sector orientation.

These more dynamic and discontinuous environments, combined with quality focused commercial postures, resulted in conflict management receiving a higher corporate priority - either directly, in the case of Aramark, or indirectly, as an unanticipated spin-off from an employee new engagement strategy in the case of Musgrave and as an adjunct to commercial transformation and the individualization of employment relations in the case of Eircom.

HR functions among the incrementalists either were, or had become, more proactive and willing to experiment with new approaches and practices, sometimes, as in the case of Musgrave, 
following the adoption of an 'Ulrich-style' HR model, comprising HR business partners, centres of excellence and shared services and a new emphasis on HR planning and strategy. Varying degrees of enthusiasm for and advocacy of ADR existed among the incrementalists. In Aramark, HR championed the wider diffusion across the multinational of the mediation programme pioneered at its Irish subsidiary, consistent with the HR objective in the firm's One Aramark strategy of offering employees internationally uniform HR policies. In Eircom, an ADR champion within HR was willing to press the case for mediation as a mechanism for promoting individualized and internally consistent employment relations policies, reflecting the firm's commercial transformation and its growing non-union workforce. That conflict management or ADR had not figured explicitly in the firm's HR employee engagement strategy and that subsequent changes in line management training and practice were not explicitly seen as a significant strategic asset, or as a means of supporting major HR objectives, may be attributed to there being no evident strong ADR champion in Musgrave. The genesis of mediation programmes in Aramark and Eircom lay in changes in the external regulatory environment governing employment discrimination, bullying and harassment and health and safety. In contrast however to improvisers, the external and internal features of these firms meant that mediation became aligned with wider evolving strategic objectives, as experience grew with ADR. In Musgrave, line management training in conflict management was an offshoot of new commercial and HR strategies that responded to an increasingly competitive and discontinuous retail market. The evolving bottom-up and adaptive alignment of ADR with wider strategic objectives that occurred in Eircom and Aramark was not evident in Musgrave, above all owing to the absence of a strong ADR champion who might have brokered such an outcome. 
Of the two strategists, Intel operated in a globally competitive market. Both strategists pursued knowledge- or innovation-focused commercial strategies. Intel was noted as a 'good employer' and the Central Bank was spurred by a concern to restore its corporate reputation as it sought to recruit a range of highly-skilled employees with more critical and challenging mindsets to support its new and extended regulatory functions. The extreme dislocation that occurred in the Irish financial sector and the creation of a new financial services regulatory regime were critical in provoking a change in the Central Bank's employment relations model. A new relationship with the Bank's unions was deemed to a significant contributor to rebuilding its corporate reputation, and innovations in collective dispute resolution were seen as integral to the shift away from what the organization termed a 'culture of confrontation' with unions towards 'co-operation, mutual gains and joint problem solving.' Intel sought to preserve an exceptionally strong unitary organizational culture; was insistent on operating on a non-union basis and regarded conflict as damaging and thus needing to be proactively managed. The HR functions of the strategists were proactive and influential - from the organizations' origins in the case of Intel. In the case of the Central Bank, HR had been forced to become more proactive as a result of the organizational crisis, and the Bank made a key appointment to a senior employment relations role. The new employment relations manager was a very strong champion of ADR. In Intel some long-serving and respected executives consistently championed ADR. The strategic reconfiguration of employment relations and conflict management practices in the Central Bank was further spurred by the Labour Court's very pointed call for a new departure in employment relations. Intel represents something of an exception with respect the influence of external institutions. Here senior executives were insistent on avoiding any encounters with external conflict resolution agencies, tribunals or Labour Courts. Institutional avoidance of this kind was a significant spur to prioritizing conflict management in 
the organization. This posture seems to have reflected the US parent corporation's policy of internalizing conflict management rather than any strong incentives in this direction that arose from the nexus of Irish conflict resolution institutions.

\section{Conclusions and Discussion}

This paper presents the first detailed study outside the US of how and why organizations adopt ADR practices. The study makes a contribution to the international literature in three areas. First, it reveals the different ways in which organizations adopt ADR innovations. It shows that some organizations turn to ADR in a reactive and improvised manner to respond to a specific problem or external development and then turn away from any further innovation. Others align ADR with strategic objectives in an incremental bottom-up manner after ADR practices have been adopted in an originally reactive manner. Yet others adopt ADR to achieve strategic goals in a top-down proactive manner. Strategists were also found to make incremental changes to ADR practices in the light of experience, or in response to new challenges, but to do so in line with the overall strategic blueprint that guided their original adoption of ADR.

This empirically grounded portrayal of patterns of ADR innovation appears to us to confound some of the existing theoretical categories, dichotomies and typologies of innovation in the literature by showing how reactive improvisers may sometimes evolve into incrementalists; how incrementalists may align ADR practices with strategic objectives in a different and more iterative and bottom-up manner than proactive strategists, and how strategists, like incrementalists, may also make ongoing changes to sets of ADR practices. The richness of the portrayal of patterns of ADR adoption revealed in the paper highlights the limitations of theoretical categories and 
typologies based on simple dichotomies such as 'reactive - proactive', as well as of prevailing understandings of the ways in which ADR may interact with strategy. Most notably, it provides a better understanding of what we term an incrementalist route to workplace conflict management innovation: a pathway, which although evident in several case studies and even prescribed in a US reform programme has remained underexplored. Highlighting this incrementalist pathway is an important contribution as previously the literature tended to emphasize that organizations either adopted ADR in an improvised ad hoc manner, or adopted a strategic approach that usually involved adopting new ADR-inspired practices in an integrated manner through CMSs. Elevating the importance of the incrementalist route to upgrading conflict management at the workplace again encourages a less binary, more open view about how organizations respond to internal and external influences that encourages them to revise established practices. Thus the analysis here suggests that no linear trajectory or 'historic transformation' may be evident, whereby organizations are moving from 'reactive to strategic,' in response to generally prevalent secular trends (Lipsky et al. 2016; 2003). It implies rather that many organizations may remain improvisers, while those we have referred to as incrementalists may evolve towards a more strategic appreciation of ADR, but may also stop short of adopting a strategic approach to conflict management.

The paper makes a second significant contribution to the literature by addressing why different patterns of innovation are found in organizations. This is an empirically and theoretically neglected question in the literature, where research often operates within silos focused around the genesis of mediation, facilitation or CMSs (Avgar 2016; Klingel 2003; Latreille 2011; Latreille and Saundry 2016; Lipsky et. al. 2016; 2012; 2003). The paper advances the literature by opening out these 
silos and by developing an integrated framework for the analysis of influences on patterns of innovation that distinguishes between the features of markets and commercial strategies, organizations, stakeholders and champions and institutions, laws and public policies. Application of this framework reveals complex configurations in which influences sometimes overlap different patterns of innovation. What emerges nevertheless is that the patterns of ADR innovation identified in the study are shaped by quite distinctive configurations of influences. Improvisation emerges as a result of regulatory changes, or major deadlocks, affecting organizations in mostly stable markets; without strong incentives for further innovation from commercial postures, organizational cultures, concern to change existing employment relations, proactive HR functions or organizational champions of ADR. Incrementalism occurs where organizations with experience of ADR innovations, often initiated in compliance with regulatory changes, respond to external and internal influences by undertaking further innovation. More competitive and discontinuous markets may interact with commercial postures focused on quality, as well as cost, with unitary/paternalistic organizational cultures, or with a concern to transform employment relations strategies, to elevate the significance of conflict management. When further supported by proactive HR functions and by management champions, ADR innovations may be seen to align with wider strategic objectives. Strategists seek to align ADR with commercial and HR priorities in two sets of conditions. First, like Intel, strategists operating in globally competitive markets and quality or innovation focused commercial postures may see ADR as a means of maintaining organizational unity and cohesion, especially when spurred in this direction by proactive HR functions and strong champions of ADR, and further incentivized by a strong concern to internalize conflict resolution as a means of avoiding engaging with external institutions. Second, like the Central Bank, strategists may adopt ADR innovations in response to disjunctive external commercial 
environments and to organizational crises - conditions seen to necessitate more proactive HR and a radical shift in employment relations. Where such developments are further reinforced by strong ADR champions and by insistent calls for radical change from external conflict resolution agencies, the resulting configuration of influences can make for strong external and internal incentives for a strategic approach to ADR. While no singular lineage leading to strategic conflict management can thus be identified, strategists share some common features: external environments that lead them to prioritize human capital, strong ADR champions and HR functions of sufficient resources and sophistication to support proactive conflict management.

The third contribution of the paper is that it questions the central premise underlying the literature equating a strategic approach to ADR with the adoption of CMSs. The analysis presented in the paper reveals that neither of the patterns in which ADR is aligned with organizational objectives - strategically/top down or incrementally/bottom-up - need result in fully-fledged CMSs. This in turn raises the question as to whether the strategic adoption of CMSs may reflect more than anything else the institutional environment of the USA. The high risks and costs and long delays associated with employment litigation in the USA (Colvin 2012) are not present to anything like the same extent in Ireland. Moreover, the picture presented in this paper for Ireland appears to mirror the pattern in other Anglo-American countries, where instances of strategic conflict management involving CMSs remain few and far between (Roche et al. 2014). What is more, the confluence of influences associated with the emergence of strategic approaches to conflict management and ADR in large US firms (Lipsky et al. 2016; 2014; 2012; 2003) may themselves be so unique as to ensure that strategic approaches of this kind may remain more the exception than the rule, in any case with regard to patterns of ADR innovation around the world. 


\section{References}

Acas (2005) Making More of Alternative Dispute Resolution. London: Advisory Conciliation and Arbitration Service.

Avgar A (2016) Treating conflict: the adoption of a conflict management system in a hospital setting. In: Lipsky DB, Avgar AC and Lamare JR (eds) Managing and Resolving Workplace Conflict. London: Emerald.

Batstone E, Boraston I and Frenkel S (1978) The Social Organization of Strikes. Oxford: Basil Blackwell.

Batstone E, Boraston I and Frenkel S (1977) Shop Stewards in Action. Oxford: Basil Blackwell.

Bendersky C (2003) Organizational Dispute Resolution Systems: a Complementarities Model. Academy of Management Review 28(4): 643-456.

Bendersky C (2007) Complementarities in organizational dispute resolution systems: how system characteristics affect individuals' conflict experiences. Industrial and Labor Relations Review 60(2): 204-224.

Beynon H (1973) Working for Ford. London: Penguin. 
Brown W (2014) Third-party processes in employment disputes. In Roche WK, Teague P and Colvin, AJS (eds) The Oxford Handbook of Conflict Management in Organizations. Oxford: Oxford University Press.

Cohen (2011) The Family, the Market and ADR. The Journal of Dispute Resolution 2011(1): 6, Available at: http://scholarship.law.missouri.edu/jdr/vol2011/iss1/6.

Colvin AJS (2003) The dual transformation of workplace dispute resolution. Industrial Relations 42: 712-735.

Colvin AJS (2004a) The Relationship between Employee Involvement and Workplace Dispute Resolution. Relations Industrielles/Industrial Relations 59(4): 671-694.

Colvin AJS (2004b) Adoption and Use of Dispute Resolution Procedures in the Nonunion Workplace. Advances in Industrial \& Labor Relations, 13: 71-97.

Colvin AJS (2012) American Workplace Dispute resolution in the Individual Rights Era, International Journal of Human Resource Management, 23(3-4): 459-75.

Conbere JP (2001) Theory building for conflict management system design. Conflict Resolution Quarterly 19(2): 215-36. 
Costantino C and Sickles-Merchant C (1996) Designing Conflict Management Systems: A Guide to Creating Productive and Healthy Organizations. San Francisco, CA: Jossey Bass.

Cutcher-Gershenfeld J, Kochan T, Barrett B and Ferguson JP (2007) Collective bargaining in the twenty-first century: a negotiation institution at risk. Negotiation Journal 23(3): 249-65.

Deukmedjian, JE (2003) Reshaping organizational subjectivities in Canada's police force: the development of RCMP alternative dispute resolution. Policing and Society 13(4): 331-48.

Eurofound (2005) Individual Disputes at the Workplace: Alternative Dispute Resolution. Dublin: European Foundation for the Improvement of Living and Working Conditions.

Ewing, JD (1990) Justice on the Job. New York: McGraw Hill

Kaminski M (1999) New forms of work organization and their impact on organizational grievance procedures. In Eaton A and Keefe JH (eds) Employment Dispute Resolution and Worker Rights in the Changing Workplace. Illinois: Industrial Relations Research Association.

Kinsella (2017) Economic and Fiscal Policy. In Roche W, O’Connell P and Prothero A. (eds) Austerity and Recovery in Ireland: Europe's Poster Child and the Great Recession. Oxford: Oxford University Press. 
Klingel S (2003) Interest-based bargaining in Education. Washington, DC: National Education Association.

Latreille P (2011) Mediation: a thematic review of the Acas/CIPD evidence. London: ACAS Research Paper, 13/11.

Latreille P and Saundry R (2016) Towards a system of conflict management? Cultural change and resistance in a healthcare organization. In Lipsky DB, Avgar AC and Lamare JR (eds), Managing and Resolving Workplace Conflict. London: Emerald.

Lipsky DB and Seeber RL (2000) Resolving Workplace Disputes in the United States: The Growth of Alternative Dispute Resolution in Employment Relations Journal of Alternative Dispute Resolution in Employment 2(3): 37-49.

Lipsky DB, Seeber RL and Fincher RD (2003) Emerging Systems for Managing Workplace Conflict: Lessons from American Corporations for Managers and Dispute Resolution Professionals. San Francisco: Jossey-Bass.

Lipsky DB, Avgar A, Lamare J R and Gupta A (2012) The antecedents of workplace conflict management systems in U.S. corporations: evidence from a new survey of fortune 1,000 companies. Paper Presented at the $16^{\text {th }}$ World Congress of the International Labour and Employment Relations Association, Philadelphia, PA. 
Lipsky DB, Avgar A, Lamare JR and Gupta A (2014) Conflict resolution in the United States. In Roche WK, Teague P and Colvin AJS (eds). The Oxford Handbook of Conflict Management in Organizations. Oxford: Oxford University Press.

Lipsky DB, Avgar AC and Lamare JR (2016) The evolution of conflict management policies in US corporations; from reactive to strategic. In Saundry R, Latreille P and Ashman I (eds). Reframing Resolution: Innovation and Change in the Management of Workplace Conflict, London: Palgrave Macmillan.

Lynch JF (2001) Beyond ADR: a Systems Approach to Conflict Management. Negotiation Journal 17(3): 207-16.

McAndrew I (2014) Med + Arb in the New Zealand Police. In Roche WK, Teague P and Colvin AJS (eds). The Oxford Handbook of Conflict Management in Organizations. Oxford: Oxford University Press.

McAndrew I (2012) Collective bargaining interventions: contemporary New Zealand experiments. International Journal of Human Resource Management 23(3): 495-510.

Purcell J (1981) Good Industrial Relations: Theory and Practice. London: Macmillan.

Roche WK and Teague P (2011) Firms and innovative conflict management systems in Ireland. British Journal of Industrial Relations 29(3): 436-459. 
Roche WK and Teague P (2012) Do conflict management systems matter? Human Resource Management 51(2):231-258.

Roche WK, Teague P, Colvin AJS (2014) The Oxford Handbook of Conflict Management in Organizations. Oxford, Oxford University Press.

Robinson, G, Pearlstein, A and Mayer, B (2005) Dyads: Encouraging Dynamic Adaptive Dispute Systems in the Organized Workplace. Harvard Negotiation Law Review 10: 339-382.

Saundry R and Wibberley G (2014) Workplace dispute resolution and the management of individual conflict - a thematic analysis of five case studies. London: ACAS Research Paper, $06 / 14$

Slichter S, Healy J and Livernash ER (1960) The Impact of Collective Bargaining on Management. Washington D.C.: The Brookings Institution.

Teague P, Roche WK and Hann D (2012) The diffusion of alternative dispute resolution practices in Ireland. Economic and Industrial Democracy 33(4): 581-604.

Ury WL, Brett JM and Goldberg SB (1988) Getting Disputes Resolved: Designing Systems to Cut the Costs of Conflict. San Francisco, CA: Jossey-Bass. 
Wood S, Saundry R and Latreille P (2014) Analysis of the nature, extent and impact of grievance and disciplinary procedures and workplace mediation using WERS2011. London: ACAS Research Paper 10/14. 
Table 1 How Organizations Adopt ADR Innovations

\section{Improvisers}

Reactive 'bottom-up' innovation.

ADR innovations adopted reactively on a case-by-case basis in response to a specific problem or external development. Innovation secluded: no further innovation or adaptation attempted and no reconfiguration of set of conflict management practices.

\section{Incrementalists}

Adaptive 'bottom-up' innovation.

Originally improvised, ADR innovations found to be effective extended or adapted to address new issues, beyond their original remit.

Innovations may become strategic by being aligned with existing or new strategic organizational objectives post hoc/following successful adoption. They may also be found ineffective and be dropped.

\section{Strategists}

Proactive 'top-down' innovation.

Systems of ADR innovations aligned with commercial strategy and strategic organizational objectives, through planning and deliberation, $a b$ initio or through systemic change programmes. 
Table 2 Telephone, focus group and case study interviews

\begin{tabular}{|c|c|c|}
\hline Methods & Roles of participants & $\begin{array}{c}\text { Numbers } \\
\text { participating }\end{array}$ \\
\hline \multicolumn{3}{|l|}{ Telephone Interviews } \\
\hline IBEC officers & Provision of HR \& IR Advice & 4 \\
\hline Trade union officials & $\begin{array}{l}\text { Representatives with experience of } \\
\text { handling individual grievances \& } \\
\text { collective conflict }\end{array}$ & 72 \\
\hline \multicolumn{3}{|l|}{ Focus Groups } \\
\hline Focus group of HR managers & Senior HR roles in organizations & 19 \\
\hline Focus group of union officials & Representatives & 7 \\
\hline $\begin{array}{l}\text { Focus groups of mediators \& } \\
\text { facilitators }\end{array}$ & $\begin{array}{l}\text { Private \& public agency mediators \& } \\
\text { facilitators }\end{array}$ & 11 \\
\hline Assisted bargaining interviews & $\begin{array}{l}6 \text { private facilitators; } 8 \text { LRC facilitators; } \\
2 \text { HSE senior managers }\end{array}$ & 16 \\
\hline \multicolumn{3}{|l|}{ Case Studies } \\
\hline Musgrave Case Study & HR managers(2) \& line managers(2) & 4 \\
\hline Intel Case Study & $\begin{array}{l}\text { Senior HR/legal manager, employee } \\
\text { relations manager, operational line } \\
\text { manager }\end{array}$ & 3 \\
\hline Eircom Case Study & $\begin{array}{l}\text { HR managers (2) and trade union officials } \\
\text { (2) }\end{array}$ & 4 \\
\hline Aramark Case Study & HR Managers (3) & 3 \\
\hline Bus Éireann Case Study & HR managers (2) & 2 \\
\hline HSE Case Study & $\begin{array}{l}\text { HR managers (2) and trade union officials } \\
\text { (2) }\end{array}$ & 4 \\
\hline $\begin{array}{l}\text { Central Bank Case Study } \\
\text { HSE Dublin, North East Case } \\
\text { Study }\end{array}$ & $\begin{array}{l}2 \text { LRC facilitators; } 2 \text { HSE senior } \\
\text { managers }\end{array}$ & $4^{*}$ \\
\hline
\end{tabular}

Total

*Included in total above for assisted bargaining interviews. 
Table 3 Case Studies of Innovations in Conflict Management

\section{Mediation at Bus Éireann}

Bus Éireann is the passenger road transport arm of the state-owned CIE group of companies, employing almost 2,400 staff. In response to several Government-sponsored initiatives on bullying and harassment, the organization with the support of the trade unions introduced a mediation option in its policy on Dignity and Respect at Work. Initially created only to address cases of bullying and harassment, such was the success of mediation that it has become the preferred method for dealing with a variety of interpersonal conflicts. A panel of internal mediators has been created and these are trained and certified by the Mediators' Institution of Ireland. But for the most part, it is considered a stand-alone policy: the success of mediation has not led to any notable change to other established collective industrial relations processes that prevail in the organization.

\section{Arbitration and Public Service Reform at the HSE}

The Health Service Executive (HSE) has responsibility for delivering all public health services in Ireland and employs over 100,000 people. For most of the 1990s and 2000s, employment relations at the HSE were characterized by an arms-length accommodation between management and unions, which slowed the pace of organizational change. However, this arms-length accommodation has been challenged by two successive National Public Service Agreements effectively grafted binding arbitration onto the collective bargaining system inside the HSE.

Externally imposed arbitration had the potential of recasting collective bargaining in the organization as presenting and justifying positions to third-party adjudicators required managers and trade unions to engage in a more deliberative manner with each other. However, this does not appear to have happened as both trade unions and management have made pragmatic improvisations to meet the challenges posed by arbitration. For the most part, management and trade unions have maintained their traditional postures and as a result the inherited arms-length accommodation employment relations system in the HSE has not been seriously disrupted. The introduction of arbitration is a classic example of plus ça change, plus c'est la même chose.

\section{Assisted Bargaining at the HSE North East}

The Health Service Executive (HSE) is responsible for delivering healthcare in Ireland and collective bargaining is used to conclude agreements between management and unions on organizational change. In 2007 the HSE proposed to reconfigure healthcare delivery in the north-east of Ireland. One proposal involved moving 80 people to different counties or Ireland. Negotiations on the move reached an impasse, however the unions and management agreed to external facilitation provided by the state dispute resolution agency, the Labour Relations Commission, a form of assisted bargaining.

The facilitation provided by the LRC, involved chairing intensive day-long negotiations based on agenda items that unions and management had been invited to submit. Agreement was reached on some areas. Remaining difficulties were referred immediately to the conciliation service of the LRC. This 'parallel process' of combining facilitated agreement on some issues and conciliation on other matters unblocked the stalemate. The LRC also became involved in facilitating the reconfiguration of services and redeployment of staff between hospitals in Dundalk and Drogheda, two towns 26 miles from each other. A similar form of facilitation led to new procedures being invented that allowed the restructuring to go ahead with the agreement of management and unions. In both cases, management and unions opportunistically used assisted bargaining to address deadlock in the collective bargaining process. Yet 
in neither case did 'assisted bargaining' spillback and encourage either party to rethink their established approach to collective bargaining, a clear cut case of improvisation.

\section{Mediation at Aramark Ireland}

Aramark Ireland is a subsidiary of a US-based multinational corporation, employing more than 4,000 full-time workers in Ireland, providing services to companies in almost 1,000 sites. Approximately 5 years ago the subsidiary in response to a public policy initiative on the topic, decided to adopt a new bullying and harassment policy. After an initial unsuccessful attempt to address bully and harassment cases through the use of investigations, the subsidiary introduced a new mediation programme to address such cases.

A small team of staff in Aramark's HR department operates the mediation programme that is actively supported by the trade unions and involves line managers being trained in mediation skills. So successful was the mediation programme in addressing bullying and harassment claims, the HR team decided to use it to address problems linked to performance management and absenteeism. The HR team considered the programme to be a success in these areas too. Within the subsidiary, mediation is now considered by the HR team as an important pillar to its conflict management policy and not simply as a pragmatic 'add-on' to its bullying and harassment policy. The HR team at headquarters too has been impressed with the Irish subsidiary's experience of mediation as it is amending its Global HR policy to encourage the rolling out of mediation in other subsidiaries - a neat example of an incrementalist approach to conflict management innovation.

\section{Proactive Line Management at Musgrave}

Musgrave is an Irish-based, family-owned multinational company with 56,000 direct employees, approximately 62 per cent of whom work in Ireland. It also runs franchises, operating under eight names in four countries. To address an ever more competitive external environment, the company sought to use established collective employment relations procedures to negotiate organizational change. But senior management became frustrated with the slow pace of change and the lack of awareness amongst employees of the need for radical action.

As a result, senior managers launched a direct communications strategy to run in parallel with collective negotiations with trade unions. This strategy involved managers engaging directly with employees via a battery of new employee engagement practices. It also required line managers meeting with employees more frequently in both one-to-one and group situations and conducting performance management reviews more systematically. Very quickly, line managers became pivotal to implementing the core strategic objectives of the organization. In addition, their problem-solving role increased substantially as their formal and informal interactions with employees multiplied. Senior managers recognized this development and started training line managers in conflict management techniques as well as tweaking other HR practices to allow them to perform their problem-solving role unencumbered. As a result, effectively by stealth, line managers are central to conflict management at Musgrave.

\section{Mediation at Eircom}

Eircom is the largest integrated telecommunications operator in Ireland with 3,500 employees, 53 per cent of whom are covered by collective agreements. Traditionally, the organization has been the testing lab for Government-sponsorship employment relations experiments in the areas of employee-share ownership and workplace partnership. Like other organizations in Ireland, mediation was first set up in Eircom to address issues of dignity and respect at the workplace. To implement the policy, a number of Eircom staff have been trained as internal mediators and external mediators are also used occasionally 
when it is deemed appropriate to do so. Mediation has been provided in cases involving individual employees, who are not willing to work together, cases where there have been allegations of bullying, and cases concerning performance management.

HR managers are satisfied that mediation allows them to deal with all staff on an equal basis and to adapt their management processes to a context in which fewer employees rely upon trade unions to represent their interests. Recently, the mediation programme has acquired a new status within the organization largely as a result of the HR team seeking to change radically the employment relations regime in the organization. In particular, it is seeking to individualize the management of the employment relationship in a thorough-going manner. Mediation is held up as emblematic of the new policies that the HR team want to diffuse. As a result, mediation is no longer viewed as a stand-alone policy, but as one element in an integrated suite of policies that are being pursued to recast the employment relations system in Eircom

\section{Multiple Innovations at The Central Bank}

The Central Bank employs about 1,400 people and is charged with the oversight and regulation of Ireland's banking and financial system. The financial crisis of 2008 rocked established organizational systems and practices at the bank. To restore credibility, senior managers thought that a process of organizational renewal was required. This strategic process involved introducing root-and-branch changes across the entire organization, including its conflict management system. Thus, the overhaul of existing conflict management procedures was part of a wider strategic endeavour to restore confidence in the Central Bank.

A newly recruited senior employee relations executive, with experience in conflict resolution and a professional interest in ADR, led the reformatting of the conflict management system at the Bank. With the assistance of a state dispute resolution agency, the Labour Court, the Bank negotiated a new industrial relations model with the main trade union. At the centre of the new model is an internal dispute resolution tribunal that was designed to adjudicate disputes that had reached an impasse. This new model was subsequently revised to allow the independent chair of the tribunal with assistance from the employer and union nominated tribunal members provide conciliation, which effectively added 'med-arb' to the work of the tribunal. Mediation was introduced too, although access to the service was contingent on a decision by a senior employee relations executive that a grievance was suitable for mediation. In a further move, the Bank's performance management system was also revamped to make provision for appealing grievances over performance ratings to an external appeals officer, as an alternative to the Bank's internal grievance procedure.

\section{Changing ADR Practices at Intel}

Intel is a sophisticated, high-tech global company. When locating in Ireland in the early nineties, it established a highly distinctive conflict management strategy that involved dividing the HR department into two functionally separate units, one that implemented mainstream HR policies and the other that provided advice, coaching and advocacy to employees when they used a newly created conflict management procedure called the Open Door process to address a problem or grievance: the organization wanted the open door process to operate independently of the HR department in the hope that it would weaken any demand for trade union recognition.

After operating the Open Door process, senior managers became concerned that it was encouraging too much formal conflict management: line managers were seen as abdicating their responsibility to solve problems informally by more or less automatically referring employees with a complaint to the Open Door process. To re-establish the principle of informal conflict management, the senior management team overhauled the Open Door process. In particular, line managers were obliged to make every effort to resolve problems informally. To weaken the formalization of problems, the HR department was 
reintegrated, ending the existence of a separate unit to provide advocacy for employees with a grievance. Although the emphasis continues to be on informal problem-solving, the HR team frequently upgrades its conflict management policy: thus recently it adopted a new innovation called 'conflict indicators' that aims to identify potential festering problems so that pro-active interventions can be made. All in all, the HR team at Intel make ongoing strategic interventions to maintain a low conflict organizational environment. 
Table 4 Influences on Patterns of ADR Innovation in Organizations

\begin{tabular}{|c|c|c|c|}
\hline & Improvisers & Incrementalists & Strategists \\
\hline & $\begin{array}{c}\text { Bus Éireann } \\
\text { Health Service Executive } \\
\text { HSE Dublin, North East }\end{array}$ & $\begin{array}{l}\text { Musgrave } \\
\text { Aramark } \\
\text { Eircom }\end{array}$ & $\begin{array}{l}\text { Central Bank } \\
\text { Intel }\end{array}$ \\
\hline \multirow[t]{4}{*}{$\begin{array}{l}\text { Markets and commercial } \\
\text { strategies }\end{array}$} & $\begin{array}{l}\text { Sheltered or partially } \\
\text { protected markets }\end{array}$ & Competitive markets & Competitive markets (Intel) \\
\hline & $\begin{array}{l}\text { Stable or gradually changing } \\
\text { markets/budgets, but } \\
\text { discontinuous change in HSE } \\
\text { Dublin, North East }\end{array}$ & $\begin{array}{l}\text { Internationalizing, or } \\
\text { operating in discontinuous } \\
\text { markets }\end{array}$ & $\begin{array}{l}\text { Highly discontinuous } \\
\text { markets/services (Central } \\
\text { Bank) }\end{array}$ \\
\hline & $\begin{array}{l}\text { Passive labour market } \\
\text { positioning }\end{array}$ & $\begin{array}{l}\text { Positioning as 'good } \\
\text { employer' }\end{array}$ & $\begin{array}{l}\text { Positioning as 'good } \\
\text { employer' (Intel) or restoring } \\
\text { corporate reputation (Central } \\
\text { Bank) }\end{array}$ \\
\hline & $\begin{array}{l}\text { Cost-focused commercial } \\
\text { priorities }\end{array}$ & $\begin{array}{l}\text { Quality- and cost-focused } \\
\text { commercial priorities }\end{array}$ & $\begin{array}{l}\text { Innovation/knowledge } \\
\text { focused commercial priorities }\end{array}$ \\
\hline \multirow[t]{2}{*}{$\begin{array}{l}\text { Organizations, } \\
\text { stakeholders and } \\
\text { champions }\end{array}$} & $\begin{array}{l}\text { Organizational cultures in } \\
\text { which conflict seen as } \\
\text { endemic }\end{array}$ & $\begin{array}{l}\text { Preservation or creation of } \\
\text { unitary organizational } \\
\text { cultures }\end{array}$ & $\begin{array}{l}\text { Preservation or creation of } \\
\text { common values/mutual gains } \\
\text { organizational cultures }\end{array}$ \\
\hline & & & $\begin{array}{l}\text { Shift to better employment } \\
\text { relations (Central Bank) }\end{array}$ \\
\hline
\end{tabular}




\begin{tabular}{|c|c|c|c|}
\hline & $\begin{array}{l}\text { Unchanging postures } \\
\text { towards unions and } \\
\text { employment relations }\end{array}$ & $\begin{array}{l}\text { Shift to better/more } \\
\text { individualized employment } \\
\text { relations (Musgrave, Eircom) }\end{array}$ & Proactive HR functions \\
\hline & $\begin{array}{l}\text { Administrative HR functions } \\
\text { No organizational champions } \\
\text { of ADR }\end{array}$ & $\begin{array}{l}\text { Proactive HR functions } \\
\text { Some championing of ADR }\end{array}$ & $\begin{array}{l}\text { Strong organizational } \\
\text { champions of ADR }\end{array}$ \\
\hline $\begin{array}{l}\text { Institutions, laws and } \\
\text { public policies }\end{array}$ & $\begin{array}{l}\text { Regulatory change: } \\
\text { discrimination, bullying \& } \\
\text { harassment } \\
\text { Public-service wide } \\
\text { agreement on mandatory } \\
\text { arbitration (HSE) } \\
\text { LRC makes facilitators } \\
\text { available (HSE Dublin, North } \\
\text { East) }\end{array}$ & $\begin{array}{l}\text { Regulatory change: } \\
\text { discrimination, bullying \& } \\
\text { harassment (Aramark, } \\
\text { Eircom) }\end{array}$ & $\begin{array}{l}\text { Strong admonition of } \\
\text { prevailing employment } \\
\text { relations model by Labour } \\
\text { Court (Central Bank) } \\
\text { Very strong emphasis on } \\
\text { avoiding engagement with } \\
\text { external conflict resolution } \\
\text { agencies (Intel) }\end{array}$ \\
\hline
\end{tabular}

